\title{
Study on the Planning Strategy of Rural Renewal under the Guidance of Villagers' Participation in Aba Prefecture
}

\author{
Meng Zhang, Bing Zhao* \\ Architecture and Urban Planning College, Southwest Minzu University, Chengdu, China \\ Email: *zhaobin_swun@sina.com
}

How to cite this paper: Zhang, M. and Zhao, B. (2018) Study on the Planning Strategy of Rural Renewal under the Guidance of Villagers' Participation in Aba Prefecture. Open Journal of Social Sciences, 6, 75-84.

https://doi.org/10.4236/jss.2019.71007

Received: December 18, 2018

Accepted: January 4, 2019

Published: January 11, 2019

Copyright $\odot 2018$ by author(s) and Scientific Research Publishing Inc. This work is licensed under the Creative Commons Attribution International License (CC BY 4.0). http://creativecommons.org/licenses/by/4.0/

\begin{abstract}
Rural revitalization is a policy introduced under the background of the integration of urban and rural development. With the government as the guide, the village-based ruling philosophy promotes rural development. In the development of this policy, the village has been further developed and adapted to the needs of the times. However, there are still a series of problems. The planning mode of the hard-working has made the participation of the villagers mostly in the form, which leads to the lack of support system and limited social development. Therefore, the formulation of villagers' participation in rural construction is the cornerstone for rural development. In various aspects, the village name was adopted to participate in the rural construction planning strategy, in order to achieve rural renewal and prosperity.
\end{abstract}

\section{Keywords}

Village Participation, Rural Construction, Planning Strategy

\section{Introduction}

In 2018, the Central Committee of the Communist Party of China issued a rural revitalization plan on the National Strategic Plan for Rural Revitalization (2018-2022), explicitly proposing to encourage farmers to use land, labor, technology as a link, carry out various forms of cooperation, and strengthen farmers as a market. The equal status of the main body, actively participates in the development of industrial integration, and creates favorable conditions for rural revitalization. In the planning, it is clearly pointed out that the importance of peasant participation plays a major role in rural development. However, in fact, rural development is dominated by local governments and enterprises, and the 
villagers' own rights are not fully reflected. Some village planning instead of playing a role in promoting rural development has to change the long-standing habits of the villagers and deviate from the significance of rural development.

\section{The Concept and Theoretical Significance of Village Participation}

\subsection{The Concept of Village Participation}

For the concept of village participation, there are different views at home and abroad. Arnstein (1969) believes that village participation is a kind of right of the people and a redistribution of rights; Smith (1984) believes that any relevant people adopt policies, plans and policies. The action; Chen Guixiang (1995) believes that the public's understanding of public policy information is the participation of villagers; Wang Zhouhu (2011) believes that individuals or organizations directly participate in public decision-making behavior is the participation of villagers. Lan Shicai (2018) defined villager participation as a planned action in his study on the model of villager participation in the construction of beautiful countryside. It refers to the two-way communication between government departments or activity organizations in the decision-making process on the principle of equality and effectiveness, and believes that villagers play a dominant role in social decision-making. Combining the above points, this paper believes that village participation is the whole process of participating in rural planning through reasonable means. In decision-making and implementation, we can express our wishes and rationalize the rural construction planning policy.

\subsection{The Significance of Villagers' Participation in Theory}

Villagers' participation is embodied in the theory of public choice that individual action is the basis of collective action and everyone is considered as the decider of decision making. At the same time, American sociologist Sherri Anstein put forward the theory of "citizen participation ladder", which divides the types of participation into three levels: the first level is the primary stage of participation, which is reflected as passive participation. The second level is the intermediate stage of participation. The third level is the high-level stage, which is carried out through the interaction between the government and professionals and villagers. At the same time, the advocacy planning theory believes that the participants are diversified and fundamental, and that planners should participate in planning based on the interests of the public, which has become the theoretical basis of western planning and the symbol of public policy transformation. At the present stage of rural Renaissance in China, the government is the dominant leader of village protection and the main body of planning. It often neglects the process of villagers' participation, resulting in the limitation of many factors such as villagers' willingness to participate, the way of participation and the degree of participation. In fact, it has not achieved the desired effect. Therefore, faced with such a dilemma, this paper mainly analyzes the problems in the process of villagers' 
participation in rural construction from the aspects of planning system, society, economy and culture, so as to put forward the planning strategy of villagers' participation, which also plays an important role in the role positioning of rural construction in the future.

\section{Domestic and Foreign Villagers Participate in Research Review and Practical Experience}

\subsection{Theoretical Research on Foreign Participation in Urban and Rural Construction}

Paul Davido (1962) proposed the theory of planning choices, and believed that the entire planning process was full of choices. Planners should not use their own judgments to determine the choice of society; Arnstein (1969) proposed that citizens participate in the ladder theory and divide the public participation into three. Levels and eight levels; Eugen Habermas (1970s) proposed an interactive planning theory that advocated the multilateral cooperation of the government-public-developer-planner and advocated that the participating entities Communication in decision-making forms a consensus; Sager (1980s) proposed the theory of liaison planning, thinking that planners use the method of contact and interaction to achieve the purpose of participation in decision-making process; Smyth (2001) proposed the theory of electronic participation ladder, targeting the public The participation ladder proposes an electronic participation ladder model including online discussion, online survey, and online decision support system. In general, the theory of public participation was carried out later, but public participation was put in the main position.

\subsection{Theoretical Research on Domestic Participation in Urban and Rural Construction}

In 1980, China officially introduced the concept of Western public participation into China. As the country continued to call for the development of a new socialist countryside, more and more policies were tilted towards the countryside. Experts in planning, political science, and economics began to pay attention to villagers in rural construction. An important position in planning. Yu Ming (1994) emphasized in the "On the implementation of villagers' autonomy and the development of rural market economy" that the villagers are conducive to promoting rural economic development, which is an objective requirement for the implementation of village management [1]; Xu Zhongping, Zhang Bin (1999) "Planning to the countryside, let the villagers come to participate in the village planning" emphasizes that planning should go to the masses, so that the people understand and participate in the planning, and ultimately bring their economic benefits [2]; Shi Xuan, Zhang Chunhui, etc. (2003) In the application of participatory methods in rural ecological restoration and conservation planning, it is believed that the participation of villagers in the planning and protection of ecological environment is conducive to enhancing the sense of ownership 
of villagers and facilitating the implementation of planning [3]. Ye Zhou (2017) analyzed the participation mechanism of villagers in the construction of the factors affecting the participation of villagers in the construction of beautiful rural villages, and believed that the villagers are the backbone of construction and development [4].

\section{Analysis of the Current Situation of Rural Construction and Village Participation in Aba Prefecture}

\subsection{The Lack of Planning System Is Limited}

In the process of rural renewal, we should first attach importance to the rural planning system. The core problem is the exploration and sorting of rural land, which cannot be separated from the participation and support of villagers. We should avoid blindly applying the urban planning system and ignoring the local rural culture. At the same time, the planning of villages should focus on multi-subject participation. The government sets up a budget, supports enterprises and other non-governmental organizations to participate in the protection planning of villages, and the village committee provides some financial assistance, and villagers are involved in the protection planning as the participants (as shown in Figure 1).

However, in recent years, villagers have not been placed as the main body in the village construction planning, which results in a deviation in decision-making [5]. In some areas, a series of imperfect plans have appeared in the task of poverty alleviation. Such as the original residential land linked to urban and rural land increase or decrease, the starting point is to improve the villagers living environment, but found the crucial poverty construction task, time is tight, work lack of provincial, state, matching funds, difficult to implement, and land compensation and resettlement interest conflicts occur, the villagers' life is hard to guarantee that the appearance of problems, the government's work difficult, the villagers' rights cannot be maintained.

Aba Prefecture has continuously improved the standards and regulations of

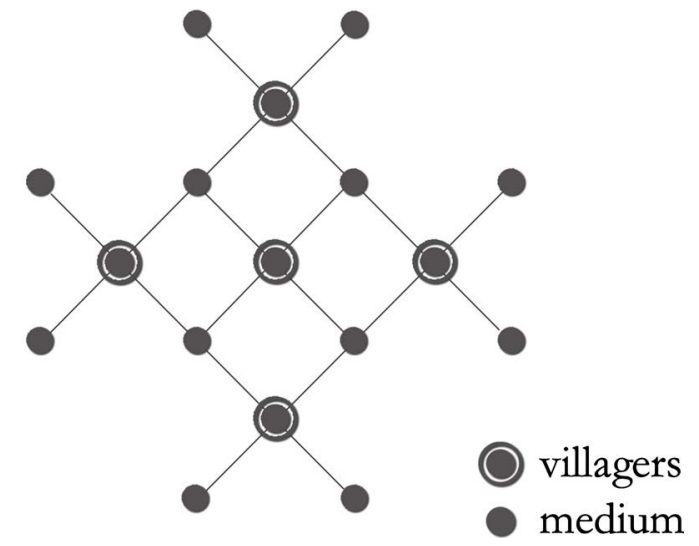

Picture source: author's own drawing.

Figure 1. Villagers' participation in the organizational structure. 
rural planning, but lacks relevant technical talents in planning technology. Some projects have not been thoroughly studied in the implementation. Although they can solve the existing problems, they cannot solve the problem. After simply referring to the city standard, the planning becomes modularized, so the phenomenon that the characteristic town is no longer characteristic, the spatial form flows into modernization, and the regional culture of diversity gradually becomes single.

\subsection{Limited Social System Limitations}

In recent years, with the development of market economy, the social communication mode of traditional villages is quietly changing. The dissolution of rural society leads to weak neighborhood relations. However, this deviates from the core of the social network construction of traditional villages in China. Its mainly embodied in the villagers and the media, the connection between the villagers and the villagers, village of previous development is based on trust each other, on the basis of the cooperation by each subject mutual support and woven network system (Figure 2), at present, the development of the village to the villagers become passive indifference, out of the village development of the social network.

Wenchuan county, Aba experienced an earthquake are eager to develop tourism economy and rebuild the area, under the government's overall planning after a disaster, most in the disaster areas to move to a new environment, proud of living space to improve, but on the other hand to improve living standards while ignoring the original cultural space, the villagers post-disaster trauma repair in mind, acquaintances society gradually disintegrated, ancient Qiang culture

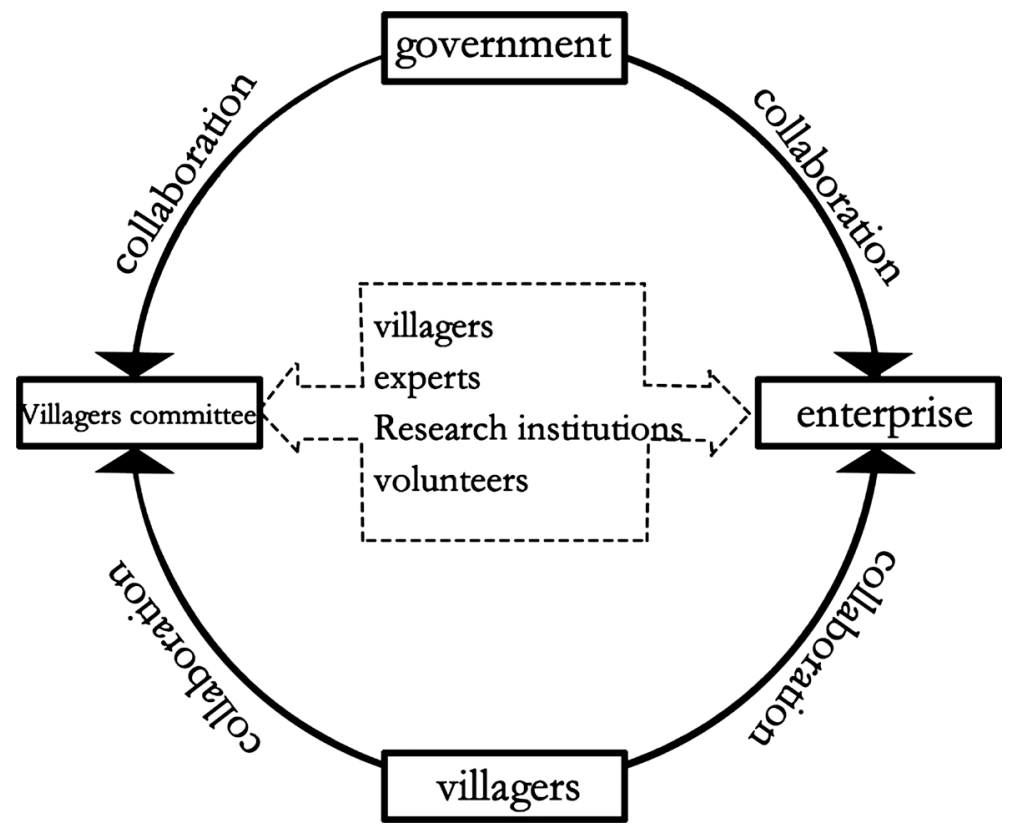

Picture source: author's own drawing

Figure 2. Model of villagers' participation in social network. 
under the background of the step by step, facing the lost, the villagers lack of identity, to speed up the rural social and cultural dislocation. At the same time, there is also the problem of uneven distribution of public resources. In the implementation process, due to the limited funds of prefecture-level governments, the public allocation of resources cannot fully cover all villagers, resulting in limited public infrastructure construction, unfair distribution of interests among villagers and difficulty in enjoying equal public resources.

\subsection{Loss of Economic Industry Is Limited}

Although Aba Prefecture has been developing its economy in recent years, its economic form is mainly based on agriculture, industry and animal husbandry. Single economic growth is limited by resources, and excessive dependence on enterprises has a greater impact. Some enterprises have not formed a benign joint promotion role with the local community, and have not enjoyed the agglomeration effect of planning and construction, which not only restricts the development of the enterprise itself, but also leads to insufficient self-hematopoietic function and the inability to introduce high-level talents. For example, the construction of Cheng'a Industrial Park relies mainly on the financial support of post-disaster reconstruction projects. When resources are limited, it will be put into use and form a funding gap. In the short term, funds cannot be returned through tax collection. For investors Chengdu and Both Aba and Fang are unbearable [6]. Lack of pillar industries, more and more local people choose to go out to work, need to develop new industries as much as possible, in order to retain talent in the village construction.

\subsection{Limited Lack of Rural Culture}

Due to the " $5 \cdot 12$ " earthquake in Wenchuan, most ancient buildings have been destroyed. The planning and construction of the new countryside has changed the original natural features. The signs of modernization are more prominent. The uniform housing planning has gradually lost the traditional pattern. With the introduction of the tourism industry, it is inevitable that there will be disorderly construction. Houses and modern building materials abound. Such places make people unable to resonate emotionally and lose their emotional sustenance. The planning of the village does not reflect the traditional culture, but also shows the imprint of tourism development. Under the guidance of the interests, the developers put the villagers in the secondary position of the planning. Instead, the tourists become the main body, and the phenomenon of the inversion of the present causes the space resources to be It is used reasonably to distort rural culture invisibly.

Taking Alcun Village, Longxi Township, Wenchuan County as an example, post-disaster reconstruction has impacted local traditional culture. The new housing pattern has affected the past blood and geography of the village, and people's exchanges have decreased. In this context, the Yi culture is facing a 
step-by-step loss. The broken building remains only the ruins of the building's external walls and yellow mud. The reconstructed Alcun replaced the stone and yellow mud with reinforced concrete, imitating the original model for construction, color and shape alone. It lacks the original features. The original fire pond of every untouchable home was replaced by a modern iron stove, and the inheritance of culture gradually faded in life. There are only a handful of villages standing on the heights of the mountains, which have become the only landmark buildings in the village. Therefore, in the planning of the neighborhood space, the ancient buildings should be strictly protected, and the sense of history and culture should be enhanced, so that the traditional culture can be passed down from one to the other revival.

\section{Villagers Participate in the Planning Strategy of Rural Construction}

\subsection{Planning Co-Editing}

Rural construction planning should reflect the concept of sustainable development. It is necessary not only to develop rural economic construction, but also to improve the quality of life of villagers, and to guide villagers to become rich in the protection of inheritance culture. Therefore, in the process of compiling planning concepts, villagers' participation should be reflected and the interests of villagers should be safeguarded. Prerequisites. In the planning, the unique cultural characteristics of the local area should be highlighted, and the planning of other areas should not be taken, and the local customs should be integrated into the planning. At the same time, we must sort out the villagers' awareness of the main body, encourage active participation in the planning, and become a member of the planning decision-making, so as to become a beneficiary in planning. When the planning is in the process of investigation, it is necessary to carry out assessment activities to understand the public opinion, issue questionnaires, visit interviews and other forms to let the villagers participate, focus on the opinions of the villagers, disclose the progress of various work, and seek public infrastructure and industry, Environmental and other recommendations are reflected in the planning process. When the preparation process should open up the planning content, let the villagers understand the policy, listen to the reasonable needs of the villagers, modify and improve the planning content, and achieve multi-agent participation.

\subsection{Social Restructuring}

The rural rejuvenation should reconstruct the "acquaintance society", and "Zhou Li, Guan Guan.Zi Ren" has the saying that "five are neighbors and five neighbors are inside". Neighbourhood relations, as an important part of residents' lives, have an important impact on people's quality of life. Good neighborhood space can make people emotionally resonate and is the place of emotional communication. Therefore, a good spatial location affects people's com- 
munication behavior. At the same time, it is necessary to have multiple complexities of space to provide rich communication activities and promote the active participation of villagers in communication. Most villages in Aba Prefecture have the relationship of clan blood, strengthen the connection between blood, guide rural acquaintances to participate in collective activities, strengthen the institutionalization and rule of law in village planning, and realize the revival of rural construction. For example, in the planning of the ancient city of Maoxian, the importance of cultural genetics is emphasized. Through regular training of embroidery culture, more and more villagers have inherited the techniques of embroidery in this process, which has also enhanced everyone's feelings.

\subsection{Economic Regeneration}

The key to rural construction is economic recovery. It can not only promote rural development, but also meet the needs of every villager. First, we must explore multiple development paths and proceed from reality to form a diversified development model. Promote the transformation of traditional agriculture, combine with modern technology, produce quality products, and move towards branding. At the same time, we must take the market as the guide, increase the income of farmers, develop the tourism economic industrial chain, and increase employment. At the same time, while promoting economic growth, we must protect the ecological environment, reduce or close high-energy-consuming and high-displacement industries, develop new industries such as forestry, tourism, and ecological economy, strengthen links with economically developed regions, and rationally allocate resources to attract. The introduction of technology, talents and equipment in developed regions will improve the overall level of enterprises.

\subsection{Cultural Return}

Rural construction should not only pay attention to the economic context, but also show the traditional culture passed down from generation to generation. Therefore, people should be based in the planning. From the perspective of the villagers, they should awaken their memory and inheritance of their own culture in the planning, so that the villagers can clearly understand the village. The direction of future development will increase the appeal of rural construction. At the same time, in the planning, the corresponding adjustments and changes should be made according to the actual situation, instead of using the theory of the propaganda to plan the local, as the famous American urban planning scholar John Friedman said in the "Use of Planning Theory", "due to the lack of people-oriented Philosophy or other preventive measures, we can only follow the trend, the established areas are neither livable nor ecologically sustainable". Therefore, people-oriented design must meet the spiritual needs of the villagers and provide them with spiritual and spiritual habitat.

Taking Aer Village, Longxi Township, Wenchuan County as an example, it 
has a long history and culture. It is known as the "three rivers and five veins, the place where the Kowloon is home". It is also the cultural heritage of Shibi. They have strong cultural beliefs, including Baishi culture. It is their common belief that it is used in the shrines, fire pits or forests of the house, and is the cornerstone of the national spirit. Therefore, when planning rural construction in Ao Village, the relationship between culture and geography is closely linked, and the villagers are the main body to establish a pleasant space for the inheritance of the culture. In addition, in the process of developing rural areas, material culture and non-material culture should also be protected, protection and inheritance mechanisms should be established, and the relationship between protection and development should be resolved. The government should also actively guide the folk culture genetics to invest in the work of protecting culture, to promote cultural exchanges and mutual progress, to jointly develop traditional culture, and thus to a new glory.

\section{Conclusion}

This paper analyzes the problems of village participation and rural construction from four aspects: planning, society, economy and culture. Firstly, it finds out the reasons for the lack of weakness in rural construction: lack of standardized legal system, limited social security, industrial imbalance of economic development, culture missing and so on. Then it summarizes the demands of the interests of villagers in all aspects of rural construction in Aba Prefecture. Taking the villagers as the main body and carrying out rural construction under the guidance of the government, the village construction will continue to benefit the villagers, and the local culture will be passed down from one source to the continuous development of the rural economic industry.

\section{Acknowledgements}

Note: This project is funded by the postgraduate innovation research project of Southwest Minzu University. Project name: Neighbourhood Space Research from the Perspective of Behavioral Characteristics-A Case Study of A'er Village of the Qiang Nationality. Project Number: CX2018SZ149.

\section{Conflicts of Interest}

The authors declare no conflicts of interest regarding the publication of this paper.

\section{References}

[1] Yu, M. (1994) Thoughts on Implementing Villager Autonomy and Developing Rural Market Economy. Civil Affairs Forum, No. 3, 21-22.

[2] Xu, Z.P. and Zhang, B. (1999) "Planning to the Countryside", Let the Villagers Participate in the Village Planning-The Successful Exploration of the Village Planning and Management Work of the Longgang Branch of the Shenzhen Municipal Bureau of Land and Resources. Special Economic Zone, No. 10, 53-54. 
[3] Shi, X., Zhang, C.H., Yang, S.W., et al. (2003) Application of Participatory Methods in Rural Ecological Restoration and Conservation Planning. Yunnan Environmental Science, No. S2, 58-61.

[4] Ye, Z. (2017) Research on the Influencing Factors of Village Participation in the Construction of Beautiful Rural Villages. Fujian Agriculture and Forestry University, Fuzhou.

[5] Qin, Z.X. (2017) Research on the Strategy of Rural Rejuvenation Planning in Southern Jiangsu under the Guidance of Villagers' Interests. Suzhou University of Science and Technology, Suzhou.

[6] Yang, C.P., Chen, S.B. and Xie, H.Y. (2015) "Enclave Economy": A New Exploration of Horizontal Ecological Compensation Mechanism-A Survey Report on the Establishment of A Industrial Park in Chengdu Aba. Macroeconomic Research, No. $5,3-8+57$. 